\title{
ATLANTIC MULTIDECADAL VARIABILITY AND THE U.K. ACSIS PROGRAM
}

\author{
R. T. Sutton, G. D. McCarthy, J. Robson, B. Sinha, A. T. Archibald, and L. J. Gray
}

The ACSIS program involves a unique grouping that will advance an integrated understanding of Atlantic multidecadal variability, a key feature of Atlantic and global climate.

$\mathrm{T}$ he North Atlantic Ocean is unusual in exhibiting variations in sea surface temperatures (SSTs) on decadal time scales that are larger in magnitude than typical subdecadal variations and comparable in magnitude to the centennial time-scale warming trend. Atlantic multidecadal variability $(\mathrm{AMV})^{1}$ is the term used to describe the decadal variability of North Atlantic SSTs, broadly characterized by decades of

AFFILIATIONS: SUTTON AND ROBSON-National Centre for Atmospheric Science, and Department of Meteorology, University of Reading, Reading, United Kingdom; MCCARTHY_ICARUS, Department of Geography, Maynooth University, Maynooth, Ireland; SINHA-National Oceanography Centre, University of Southampton, Southampton, United Kingdom; ARCHIBALD-Department of Chemistry, University of Cambridge, Cambridge, United Kingdom; GraY-Department of Atmospheric, Oceanic and Planetary Physics, University of Oxford, Oxford, United Kingdom CORRESPONDING AUTHOR: Gerard D. McCarthy, gerard.mccarthy@mu.ie

The abstract for this article can be found in this issue, following the table of contents.

DOI:I0.II75/BAMS-D-16-0266.I

In final form 4 July 2017

(C)2018 American Meteorological Society

For information regarding reuse of this content and general copyright information, consult the AMS Copyright Policy. basinwide warm or cool anomalies, relative to the global mean.

AMV has been linked with substantial climate impacts in many parts of the world, both on the continents surrounding the North Atlantic and farther afield, such as in South and East Asia. These impacts involve, for example, decadal variations in temperature and rainfall patterns, hurricane activity, and sea level changes (e.g., Knight et al. 2005; Buckley and Marshall 2016). In some cases the magnitude of these impacts is sufficient that, on time scales up to a few decades, the AMV influence may dominate over the influence of longer-term climate change.

Given its importance, understanding the physical processes that drive AMV and the extent to which its evolution is predictable is a key challenge in climate science. It is clear from past research that interactions between the ocean and atmosphere play a key role in $\mathrm{AMV}$, but the detailed interactions are poorly understood. They may involve not only ocean and

\footnotetext{
${ }^{1}$ The term Atlantic multidecadal oscillation (AMO) also exists in the literature. However, to some readers the word oscillation implies a specific preferred time scale (i.e., spectral peak), which may or may not exist in reality. The term AMV is deliberately more generic and-particularly at the current state of knowledge-more appropriate.
} 
atmosphere circulation but also important aspects of atmospheric composition, notably aerosols. Furthermore, interactions with the cryosphere-both Arctic sea ice and the Greenland Ice Sheet-could also be involved. It is clear, therefore, that developing a full understanding of $\mathrm{AMV}$ requires a multidisciplinary approach.

The 5-yr (2017-21) North Atlantic Climate System Integrated Study (ACSIS) was conceived to address the complex problems of AMV and related research challenges. It has been designed to exploit the new opportunities presented by the unprecedented wealth of sustained, multivariate, observational records that is now available for the North Atlantic region and the latest advances in numerical simulation. It is particularly timely because of evidence that a change in the phase of AMV may be happening now (Robson et al. 2016), creating an unprecedented opportunity to observe the processes responsible unfold.

ACSIS is being delivered by seven of the United Kingdom's leading environmental research institutes, who together enable the multidisciplinary approach that the science challenges demand.

This short article provides a high-level review of current knowledge concerning AMV observations and mechanisms and outstanding research questions, together with an overview of the ACSIS program.

\section{OBSERVED CHARACTERISTICS OF AMV.} The evolution of North Atlantic mean SST anomalies over the past 150 years, and an AMV index based on the difference between North Atlantic SSTs and SSTs averaged over the rest of the world's oceans, is shown in Fig. 1a. The AMV index was negative (i.e., cool phase) in the periods (approximately) $1890-1920$ and 1965-95 and positive (i.e., warm phase) in 1925-60 and 2000-present.

Although the AMV index is defined as a basinmean index, there is considerable regional structure to the SST anomalies (Fig. 1d). The SST anomalies are largest, in terms of magnitude and variance explained, in the subtropical-to-subpolar region $\left(30^{\circ}-65^{\circ} \mathrm{N}\right)$. However, AMV-related SST anomalies are also found to reach down into the tropical North Atlantic in a so-called horseshoe pattern. Details of the pattern are, to some extent, sensitive to the exact definition of the AMV index and the dataset used; specifically, the magnitude of the tropical SST anomalies can be sensitive to the detrending method and to the period of data used (Trenberth and Shea 2006). This sensitivity is not entirely surprising, given in this region compared to the extratropics. Finally,

| BATIS FEBRUARY 2018 should be noted that AMV is not associated with purely standing pattern of SST anomalies; on the contrary, the pattern evolves spatially (Hodson et al.

Changes in ocean circulation have long been hypothesized to be an important driver of AMV, but thi link has not been proved directly because of a lack of deep-ocean observations. However, there are observational "proxies" of ocean circulation. Figure lb shows two such proxies: Labrador Sea density (Robson et al. 2014), which is a proxy for deep water that contributes to the cold, return branch of the Atlantic meridional overturning circulation (AMOC), and a sea level index (McCarthy et al. 2015a), which relates to the strength of the circulation between the subtropical and of and in in the latter half of the twentie th century, particularly the 1990s shift to positive AMV. Other factors that may contribute to driving AMV variability include changes in anthropogenic sulfur dioxide $\left(\mathrm{SO}_{2}\right)$ emissions (Fig. 1c; Booth et al. 2012) and changes in atmospheric circulation, illustrated in Fig. le by the North Atlantic Oscillation (NAO) index. Persistent phases of the NAO have led AMV phase changes in the past, such as during the 1960s and 1990s.

Figure 1 shows two of the impacts that have been linked to AMV (e.g., Zhang and Delworth 2006). Figure if shows that hurricane numbers were relatively low from 1965-95, which corresponded to a cool phase of AMV. There is also evidence for multidecadal variability in hurricanes farther back in time, but the observations become more uncertain. Figure Ig shows that summer [June-September (JJAS)] Sahel rainfall dropped dramatically from the 1950s to the 1970s, which was also associated with the onset of the AMV cool phase. Sahel rainfall has recovered somewhat since the 1980s, as the AMV index has risen, but it still has not returned to it 1950s peak.

AMV MECHANISMS. The evidence from proxy climate records (e.g., Chylek et al. 2011) strongly suggests that AMV is not limited to the period of in trumental observations during which there has been significant anthropogenic forcing of the climate system. Therefore, it appears that AMV is fundamentally natural phenomenon, albeit one that may have been modified in recent times by anthropogenic forcings. This view is further supported by evidence from long unforced (control) simulations with global climate models, many of which exhibit modes of decate or multidecada variability focused on the North
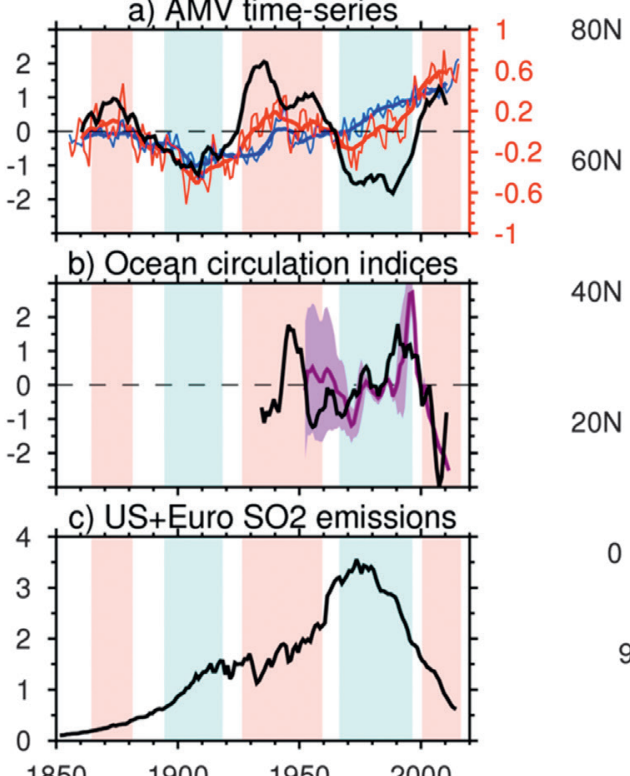

$40 \mathrm{~N}$

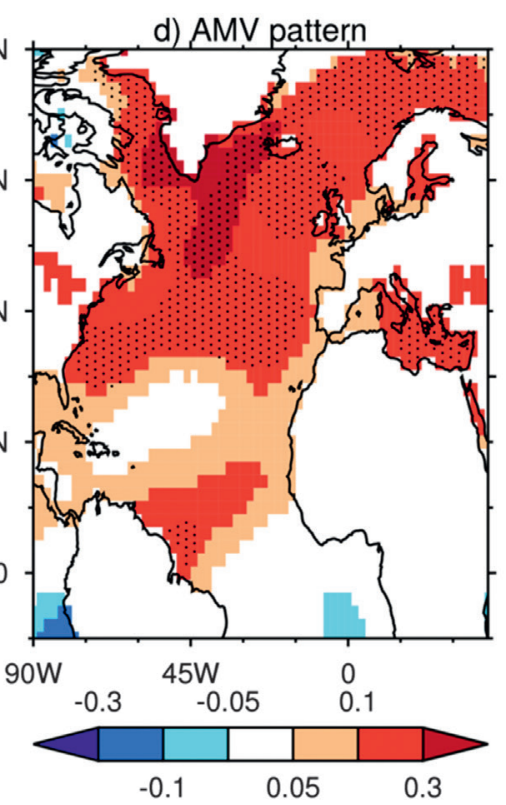

$\begin{array}{ll}-0.1 & 0.05\end{array}$ e) D.JFM NAO index

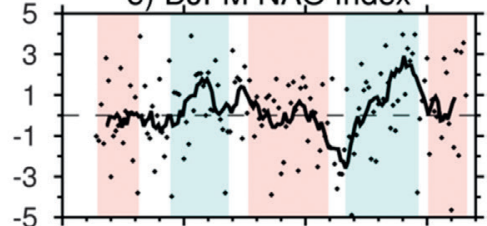

f) Hurricanes

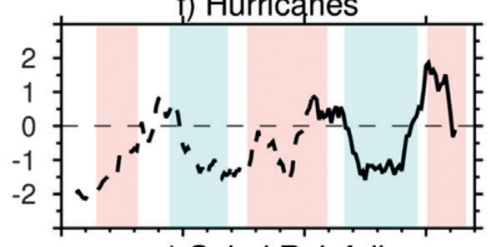

g) Sahel Rainfall

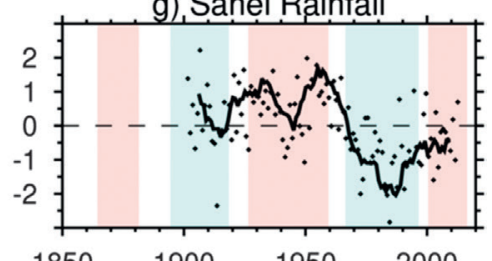
North Atlantic (blue) sea surface temperatures for annual means (thin lines) and decadal mean (thick lines) based on the Extended Reconstructed SST, version 4 (ERSST.v4), dataset (Huang et al. 2015). Units are ${ }^{\circ} \mathrm{C}$ and anomalies are made relative to the entire $1855-2016$ period. The AMV index is shown in black, which is the normalized difference between the 10-yr smoothed Atlantic (red) and global-mean (blue) indices. This definiindex is larger tha 0.5 or smaller than -0.5 are highlighted with red and blue filled sections, respectively. (b) Ocean circulation proxies, including the sea level dipole index (black) based on McCarthy et al. (2015a) and (be $1,000-2,500$-m Labrador Sea density index (purple) from Robson et al. (2014). Purple shading shows the 5\%-95\% confidence interval for the deep Labrador Sea density. (c) The emissions of SO from the United States and Europe from the CMIP6 emissions dataset. (d) The SST pattern associated with the AMV index, represented by the regression slope between the AMV index in (a) and the annual-mean SST anomalies at each grid point over the period 1990-2016. Stippling is a measure of signal to noise and shows where the variance explained is $>\mathbf{2 0} \%$ of the interannual variance at each grid point, after a linear trend has been removed. (e) The Dec-Mar (DJFM) NAO station index data (Hurrell et al. 2003); black dots show individual years, and the thick black line shows the 10-yr running mean. $(f)$ The accumulated cyclone energy from 1948 to 2016 from the National Hurricane Center (NHC) "best track" hurricane database (HURDAT) (solid; Landsea et al. 2004) and from 185 to present (dashed). (g) JJAS rainfall anomalies over the Sahel $\left(10^{\circ}-20^{\circ} \mathrm{N}, 20^{\circ} \mathrm{W}-40^{\circ} \mathrm{E}\right)$ from the GPCC datase (Schamm et al. 2014); dots show the annual means and the black curve shows the $10-y r$ running mean. All time series are normalized by their standard deviation, apart from the blue and red curves in (a).

Atlantic (e.g., Delworth and Mann 2000; Knight et al. 2005) Such modetsinghtions typically show that variability in Atlantic Ocean northward heat transport (OHT) plays a central role in the generatio of AMV, although there has been some recent deba on this point (Clement et al. 2015; Zhang et al. 2016; Clement et al. 2016).

Variability in atmospheric circulation associate with the NAO modulates air-sea fluxes, particularly over the Labrador Sea and wider subpolar gyre. The positive phase of the NAO causes enhanced cooling of the subpolar North Atlantic, which increases seawater density and formation of deep water (e.g., Delworth et al 2017). The subsequent cean adjustment involving wave and advective processes, leads to a spinup of the AMOC and hence increases in OHT, warming SSTs (Fig. 2). This picture linking deep-water formation and an enhanced AMOC belies some of the complexities of water mass pathways and connectivities between regions of deep convection and broader circulation (Lozier 2012) but, nonetheless, remains a robust paradigm for understanding climate-scale interactions between the NAO, AMOC, and AMV (e.g., McCarthy et al. 2015a). It also includes the possibility for a delayed negative feedback as enhanced OHT leads to a warming of the subpolar gyre and hence a decrease in seawater density. This decrease in density acts to slow the ocean circulation and reduce $\mathrm{OHT}$. The detailed processes through which the ocean circulation and OHT adjust to variability 


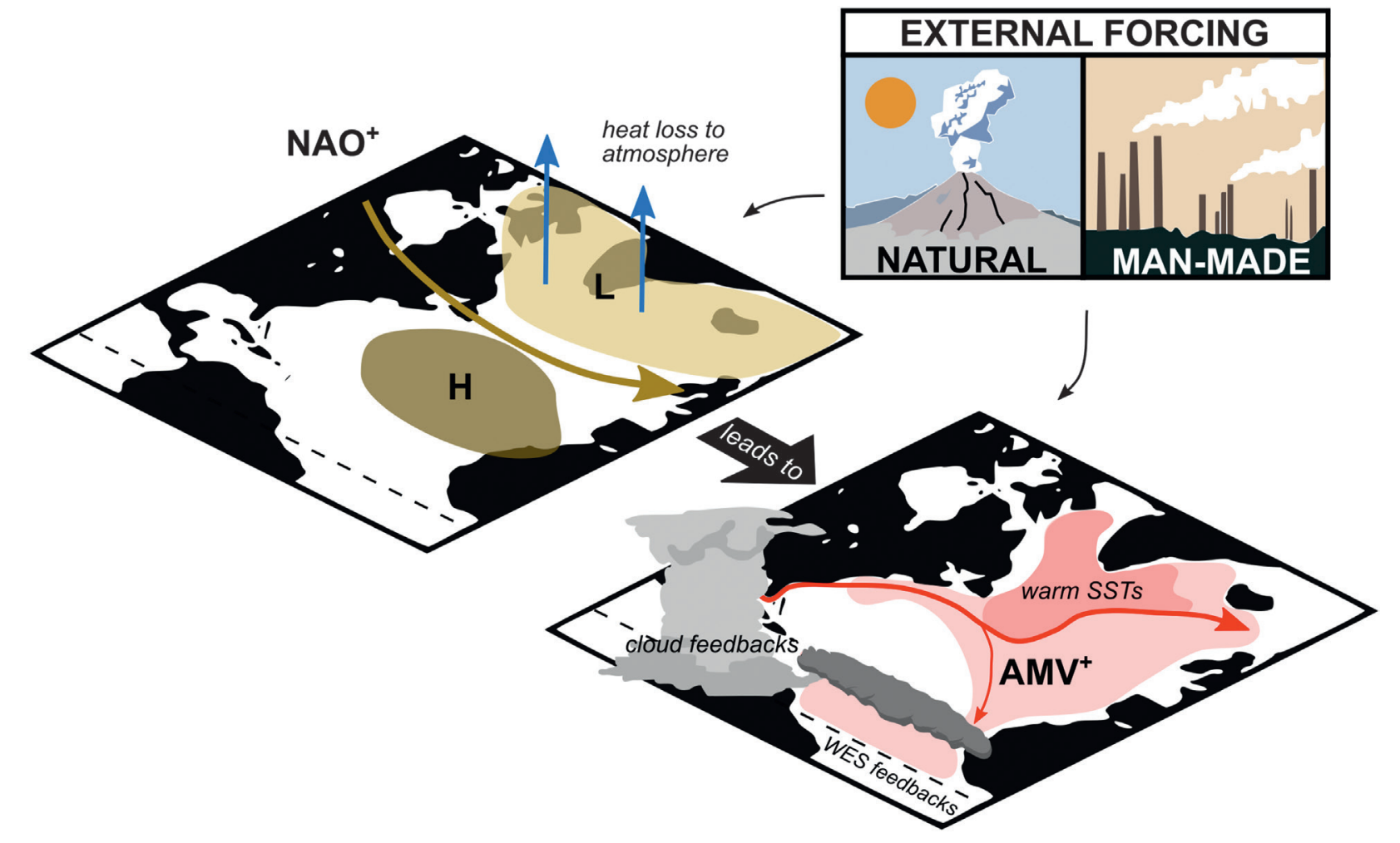

FIG. 2. Schematic illustrating processes involved in AMV. The left-hand map shows typical NAO+ conditions with the Greenland low $(\sim 1,010 \mathrm{hPa})$ and the Azores high $(\sim 1,020 \mathrm{hPa})$ highlighted with the storm track illustrate between (brown arrow). $\mathrm{NAO}^{+}$conditions result in heat loss from ocean to the atmosphere, particularly over $\mathrm{AMV}^{-}$. Increased deep convection is linked with increasing northward ocean heat transport (red arrows), as sociated with a strong AMOC, leading to warmer SSTs, indicative of $\mathrm{AMV}^{+}$, as shown in the right-hand map. External forcing from natural solar and volcanic variability and from manmade aerosols have been proposed as additional drivers of AMY. Ocean-atmosphere feedbacks are important in the amplification and modification of AMV patterns including interactions with tropical and subtropical clouds and WES interactions.

in air-sea fluxes are poorly understood, but the relevant time scales are decadal, and it is likely that these processes play an important role in setting the time scale of AMV.

The OHT feedback is the simplest feedback that appears to shape AMV but is by no means the only one. There is evidence for many other feedbacks, the relative importance of which are very uncertain. Potential feedbacks include the following:

1) Variability in the Atlantic Ocean northward transport of freshwater, which also affects seawater density and hence ocean circulation. This is likely to be a positive feedback.

2) Ocean-atmosphere coupling. AMV-related changes in SSTs may influence atmospheric circulation in the extratropics (including the NAO; see Fig. 3) or in the tropics, where shifts in the intertropical convergence zone maybe an important factor. SST changes in the tropics and subtropics

may be amplified or modified by wind-evaporation-SST (WES) feedback, cloud feedbacks, and feedbacks involving the lofting and transport of Saharan dust (Yuan et al. 2016).

Interactions with the cryosphere. Warming of the subpolar North Atlantic can accelerate the melting of Arctic sea ice and may have been a factor Sheet. The resulting freshwater can potentilly modify seawater densty and hence ocean cirilation, as in point 1 . There is sonce ocean circuthis feedback is 1 . There some evidence that scales than those associnportant on longer time scales than those associated with AMV (Böning et al. 2016).

Interactions with other ocean basins. For example, there is strong evidence that transport of freshwater is an important factor for interactions with the Arctic Ocean (e.g. Jungclaus et al. 2005). Interactions with the Indian Ocean may occur through the Agulhas Current. Atmospheric tele-

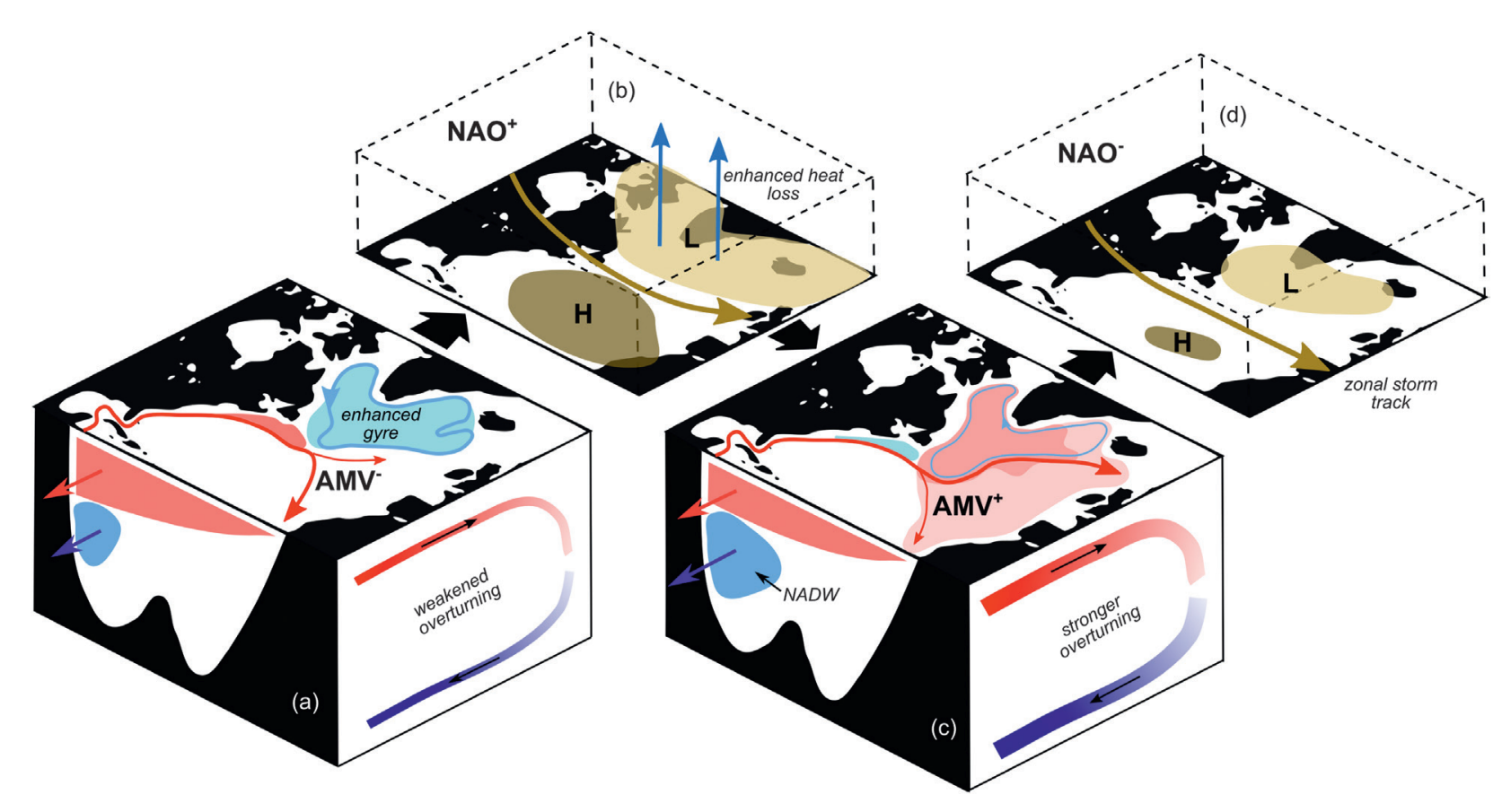

FIG. 3. Schematic illustrating one mechanism for AMV phase reversal. (a) A cool phase of the AMV is associated ened overturning circulation. The increased meridional gradient of SSTs is conducive to (b) $\mathrm{NAO}^{+}$conditions, which, as shown in Fig. 2, spin up the overturning circulation by increasing the production of North Atlantic Deep Water (NADW). The AMV' conditions resulting from the increased northward heat transport erode the meridional gradient of SST and lead to conditions favoring (d) $\mathrm{NAO}^{-}$. Predominant $\mathrm{NAO}^{-}$conditions weaken the overturning, returning to (a).

connections can also support interactions with the Indo-Pacific Ocean (e.g., Timmermann et al. 1998; Dong and Sutton 2002; McGregor et al. 2014).

provide some of the motivation for the ACSIS program, described in the section titled "The U.K. ACSIS program." Some of the key research questions are as follows:

As already noted, AMV may be influenced by external forcing factors (such as highlighted in Fig. 2). has been suggested that natural forcings-volcanic eruptions and solar variability - might act as a pacemaker for AMV, possibly setting its phase and influencing its amplitude (Otterå et al. 2010; Swingedouw et al. 2015; Thiéblemont et al. 2015). Anthropogenic forcings, particularly aerosols and greenhouse gases could play a similar role (Booth et al. 2012), but there has been some controversy about their importance (Zhang et al. 2013; Robson et al. 2016). Aerosols can modify surface radiation and hence SST but are also influenced by changing wind patterns, so it is possible that two-way interactions between the physica aspects of the North Atlantic climate system an atmospheric composition could play a role in AMV.

It is evident from this discussion that AMV is a complex phenomenon, albeit with a simple feedback at its heart. From a research perspective there are many outstanding questions, and these question

What factors control the amplitude, time scale, and phase of AMV?

What is the strength and relative importance of the feedbacks that shape AMV?

Which are the most important external forcing factors?

To what extent do they influence AMV and through what mechanisms?

DECADAL PREDICTION FOR THE NORTH ATLANTIC REGION. Because of the important societal impacts associated with AMV, and the association of AMV with slow, potentially predictable changes in the ocean, there has been considerable interest in predicting how the Atlantic might evolve years to decades ahead. Interestingly, the North Atlantic appears to be one of the most predictable regions at these lead times (Kirtman et al. 2013; Yeager and Robson 2017). Several prediction systems show skill for AMV at multiyear lead times, and there is 
emerging evidence that skillful prediction of AMV can lead to skill in predicting societally relevant climate impacts, such as the number of hurricanes and Sahel rainfall (Smith et al. 2010; Sheen et al. 2017). However, SSTs in the tropical North Atlantic, which appear to be important for many climate impacts, are not currently predicted as well as those at higher latitudes (García-Serrano et al. 2015). Realizing the full potential of decadal prediction for the North Atlantic region is a major research challenge and opportunity. ACSIS will undertake further detailed mechanistic analysis of state-of-the-art decadal predictions in order to understand the processes contributing to improved skill.

THE U.K. ACSIS PROGRAM. The ACSIS program is challenges raised by AMV and related research questions. The overarching aim is to enhance the capability to detect, attribute, and predict changes in the North Atlantic climate system. ACSIS explicitly recognizes the central role of interactions in shaping the evolution of the North Atlantic region. These interactions occur between components of the physical climate system-atmosphere, ocean, and cryosphere-and between the physical climate system and aspects of atmospheric composition. There is a particular focus on decadal time-scale changes that have happened recently and are ongoing (notably the AMV phase change; Robson et al. 2016) because these are the best observed changes and understanding them is key for near-term predictions.

ACSIS involves an innovative partnership between seven U.K. environmental research centers: six funded by the Natural Environment Research Council (NERC) plus the Met Office. It was developed in response to a specific initiative from NERC to forge strategic collaborations to address major problems in environmental science. The program is led by the National Centre for Atmospheric Science (NCAS) and involves the National Oceanography Centre (NOC), the British Antarctic Survey (BAS), the National Centre for Earth Observation (NCEO), the Centre for Polar Observation and Modelling (CPOM), and the Plymouth Marine Laboratory (PML). There are also important U.S. partners: the National Center for Atmospheric Research (NCAR), the National Oceanic and Atmospheric Administration (NOAA), Duke University (DU), University of Miami (UoM), University of Oregon (UoO), The University of Texas at Austin (UTA), and Harvard University (HU). These partners collaborate on specific components of the program, contributing

| BAIIF FEBRUARY 2018 complementary expertise in ocean observations and modeling (DIU, UoM, NOAA, and UTA), climate modeling oO and $\mathrm{HU}$.

The specific science objectives are as follows:

to provide a quantitative, multivariate description of how the North Atlantic climate system is changing;

2) to determine the primary drivers and processes that are shaping change in the North Atlantic climate system now and will shape change in the near future; and

3) to determine the extent to which future changes in the North Atlantic climate system are predictio.

To address these questions in depth requires a very diverse range of sustained observations and syntheses, together with world-leading simulation capabilities for the atmosphere, ocean, cryosphere, and the fully coupled climate system. Figure 4 illustrates the breadth of the ACSIS observing system, stretching from the deep ocean to space.

From the top of the atmosphere to the surface of the Earth, ACSIS is supporting observations and analyses of the evolving composition of the atmosphere in the North Atlantic region. These include sustained in situ mear A dom at Pente don, at Penlec Point-boh atmospheric observatorie contributing to our understanding into atmospheric composition change near the surface and combined with bespoke modeling simulations enabling new insight into the budgets of tropospheric ozone and methane. New aircraft missions, using the Facility for Airborne Atmospheric Measurements (FAAM) modified BAe-146 Atmospheric Research Aircraft (ARA), will be used to survey changes in aerosols and trace gases in the free troposphere over the period 2017-21. Sorties with the ARA from the United Kingdom to the zores will provide a crucial comp A will will produce the longest record of composition change the lower free troposphere over the North Atlantic. One of the most outstanding questions related to the composition of the atmosphere is understanding the causes for changes in the oxidizing capacity of the troposphere and how this affects trends in powerful greenhouse gases like ozone and methane (Parrish et al. 2014; Turner et al. 2017). In ACSIS, we will make sustained measurements of ozone and methane both at our ground-based locations and on the ARA and use bespoke model simulations to understand the causes for changes in the observations made over time. Analyses of these exciting new data will enable improvements in our understanding of the role of anthropogenic and natural forcers within the North Atlantic basin. Linking with the National Aeronautics and Space Administration (NASA) Atmospheric Tomography Mission (ATom) project (Prather et al. 2017) will (Prather et al. 2017) will derstanding of global atderstanding of global at-
mospheric composition mospheric compositio
change and impacts.

change and impacts. From the ocean surface
to the seafloor, ACSIS will to the seafloor, ACSIS will utilize existing in situ observations and remotely sensed SST, sea surface height, and sea ice concentration. The subsurface ocean is covered by a combination of the Argo float array (Freeland et al. 2010), from which ocean heat content can be derived, and basinwide mooring arrays measuring ocean overturning and meridional heat transport at $26.5^{\circ} \mathrm{N}$, the Rapid $\mathrm{Cli}^{-}$ mate Change (RAPID)Meridional Overturning Circulation and Heatflux Array (MOCHA)-Western Boundary Time Series (WBTS) mooring Series (WBTS) mooring array (McCarthy et al. 2015b), and in the North Allantic Subpolar Gyre [the Overturning in the Subpolar North
Atlantic Program (OSNAP) Atlantic Program (OSNAP) mooring array; Lozier et al. 2017]. These observations a surface glider in the telemetry of near-real-time data will be used in new estimates and uncertainties of will combine Earth observation satellites with in situ measurements to provide volume estimates of Arctic sea ice and the Greenland Ice Sheet. New technology development will be supported with the integration of

ACSIS is also undertaking core numerical model simulations of the ocean, atmosphere (including sophisticated atmospheric chemistry), and cryosphere. The approach is to perform state-of the-art global simulations of ocean-ice, atmosphere, and 
atmospheric composition separately and in addition to model all components together as a coupled system. All the simulations will be evaluated against the ACSIS observations and complementary datasets, such as ocean and atmospheric analysis and reanalysis datasets. A particular focus is on high-resolution simulations going well beyond that typical of models used for climate projections. Thus, atmosphere-only simulations, forced by observed sea surface temperature from 1950 to present at resolutions of 60 and $25 \mathrm{~km}$, both with 85 levels in the vertical, allowing for good resolution of the stratosphere will be performed. Corresponding ocean-ice simulations, forced by observed surface atmospheric conditions, will be run from 1958 to present at $1 / 4^{\circ}$ and $1 / 12^{\circ}$ resolution. Simulations of atmospheric composition will be performed in which the circulation is nudged toward the observations. Sensitivity tests will enable investigation of the role of specific processes in explaining observed changes in both atmospheric and ocean composition and circulation. ACSIS will also run high-resolution fully coupled simulations with atmosphere and ocean-ice resolutions of $25 \mathrm{~km}$ and $1 / 4^{\circ}$ for the period $1950-2050$ and an even higher coupled simulation at $25 \mathrm{~km}$ and $1 / 12^{\circ}$. The coupled simulations will enable investigation of the relative roles of the different external forcing processes (solar and volcanic inputs, naterand ing processes (so ar and volcenicin ins, anthropompared to unforced variabilty in explaining observed changes on decadal time scales. All our simulations, of the Ocean (NEMO)-Los Alamos Sea Ice Model of the Ocean (NEMO)-Los Alamos Sea Ice Model (CICE); Madec 2008; Hunke and Lipscomb 2008], atmosphere-only Hadley Centre Global Environment Model, version 3, Global Atmosphere (HadGEM3GA); Walters et al. 2011], atmospheric composition [U.K. Chemistry and Aerosols (UKCA) model; Morgenstern et al. 2009], and coupled [Hadley Centre Global Environment Model, version 3, Global Coupled configuration 3 (HadGEM3-GC3). see Willimouled 2015] willbe (Jones et al. 2011), which will provide climate projections contributing to the phase 6 of the Climate Model Intercomparison Project (CMIP6), and simulation data will be made freely available to the academic research community.

To ensure the observational and modeling components of ACSIS are brought together effectively to address the science goals, management of the program is organized around four themes, each of which has a theme leader. The themes are atmospheric composition, ocean-ice, atmosphere-climate, and synthesis. The synthesis theme, which ims to integrate understanding of the fully coupled system, including attribution and predictability of the early synthesis "Ctivities has been a report on "Changes in the North tlantic climate system 2005-2016" (Robson et al. 17, manuscriopt submitted to Int. J. Climatol.). nother key activity is the development of a set of Atlantic climate system indicators, which will be made available through the ACSIS project website (www.acsis.ac.uk). These indicators are designed to characterize the multivariate state of the North Atlantic climate system and recent changes-exploiting the diversity of sustained observations that is now available - and to provide a focal point for North Atlantic climate system research and fort for on of audi. 政er aspects of the ocean state, atmospheric circulation nd composition, and the cryosphere. By making hese indicators available together, and updating them regularly, an integrated view of the changing North Atlantic climate system will be presented.

CONCLUDING REMARKS. This brief article has aimed to illuminate the complexity and breadth forcings, mechanisms, and feedbacks th 作 a tive capable o telivering an innovative and integrated approach advance understanding of AMV. AMV is of crucial societal importance in many regions of the globe, fa eyond the borders of the Atlantic. Ultimately, an mproved understanding will lead to better decadal predictions that can be used in preparation and mitigation in response to this climate variability. The time is ripe to advance our understanding of AMV as, in spite of ever-rising global temperatures, the Atlantic egion is lagging behind. If this lag marks the onset f 1970s and 1980s, then droughts (and poted in (and potentia 列 long the densely populated U.S. East Coast, could some of the consequences. Furthermore, since the last negative AMV phase, climate change has continued apace: water stress levels and mean sea levels are higher, suggesting a new negative phase might have more extreme consequences than in the past. Hence, understanding AMV has never been more important. If other research organizations or cientists are interested in collaborating with ACSIS contact can be made through the ACSIS website (www.acsis.ac.uk/contact-us).
ACKNOWLEDGMENTS. The ACSIS program is funded by the U.K Natural Environment Research Concil. The authors acknowledge the esential con of all the of all the institutions and the large group of staff that are involved in delivering the program.

REFERENCES

Böning, C. W., E. Behrens, A. Biastoch, K. Getzlaff, an J. L. Bamber, 2016: Emerging impact of Greenlan meltwater on deepwater formation in the North Atlantic Ocean. Nat. Geosci., 9, 523-527, https://do .org/10.1038/ngeo2740.

Booth, B. B N N J Dunstone, P. R. Halloran, T. Andrews and N. Bellouin 2012: Aerosols im, Andrews, prime drier of twetieth-century North Atlantic climate variability. Nature, 484, 228-232, https://d .org/10.1038/nature10946.

Buckley, M. W., and J. Marshall, 2016: Observations, inferences, and mechanisms of the Atlantic meridiona overturning circulation: A review. Rev. Geophys., 54, 5-63, https://doi.org/10.1002/2015RG000493.

Chylek, P., C. K. Folland, H. A. Dijkstra, G. Lesins, and M. K. Dubey, 2011: Ice-core data evidence for a prominent near 20 year time-scale of the Atlantic multidecadal oscillation. Geophys. Res. Lett., 38, L13704, https://doi.org/10.1029/2011GL047501.

Clement, A., K. Bellomo, L. N. Murphy, M. A. Cane, T. Mauritsen, G. Rädel, and B. Stevens, 2015: The Atlantic multidecadal oscillation without a role for ocean circulation. Science, 350, 320-324, https://do .org/10.1126/science.aab3980.

-, M. A. Cane, L. N. Murphy, K. Bellomo, T. Mauritsen, and B. Stevens, 2016: Response comment on "The Atlantic multidecadal oscillation without a role for ocean circulation." Science, $\mathbf{3 5 2}$ 1527-1527, https://doi.org/10.1126/science.aaf2575.

Delworth, T. L., and M. E. Mann, 2000: Observed an simulated multidecadal variability in the Northern Hemisphere. Climate Dym, 16, 661-676, https/10 (1007/ 00382000075.

, Zeng, L. Zhang, R. Zhang, G. A. Vecchi, and X. Yang, 2017: The central role of ocean dynamics in connecting the North Atlantic Oscillation to th extratropical component of the Atlantic multidecad oscillation. J. Climate, 30, 3789-3805, https://do .org/10.1175/JCLI-D-16-0358.1.

Dong, B.-W., and R. Sutton, 2002: Adjustment of the coupled ocean-atmosphere system to a sudden change in the thermohaline circulation. Geophys. Res. Lett., 29 1728, https://doi.org/10.1029/2002GL015229.

Freeland, H. J., and Coauthors, 2010: Argo-A decade of progress. Proc. OceanObs'09: Sustained Ocean
Observations and Information for Society, Vol. 2, ESA Special Publication WPP-306, Venice, Italy, European Space Agency, 357-370.

García-Serrano, I., C. Frankignoul, G. Gastineau, and A. De La Càmara, 2015: On the predictability of the winter Euro-Atlantic climate: Lagged influence of autumn Arctic sea ice. J. Climate, 28, 5195-5216, https://doi.org/10.1175/JCLI-D $-14-00472.1$.

Hodson, D. L. R., J. I. Robson, and R. T. Sutton, 2014: An anatomy of the cooling of the North Atlantic Ocean in the 1960s and 1970s. J. Climate, 27, 8229-8243, https://doi.org/10.1175/JCLI-D-14-00301.1.

Huang, B., and Coauthors, 2015: Extended reconstructed sea surface temperature version 4 (ERSST. v4). Part I: Upgrades and intercomparisons. J. Climate, 28, 911-930, https://doi.org/10.1175/JCLI-D-14 -00006.1 .

Hunke, E., and W. Lipscomb, 2008: CICE: The Los Alamos Sea Ice Model. Documentation and software, version 4.0. Los Alamos National Laboratory Tech. Rep. LA-CC-06-012, 73 pp.

Hurrell, J. W., Y. Kushnir, G. Ottersen, and M. Visbeck, 2003: An overview of the North Atlantic Oscillation. The North Atlantic Oscillation: Climatic Significance and Environmental Impact, Geophys. Monogr., Vol. 134, Amer. Geophys. Union, 1-35.

Jones, C., and Coauthors, 2011: The HadGEM2-ES implementation of CMIP5 centennial simulations. Geosci. Model Dev., 4, 543-570, https://doi .org/10.5194/gmd-4-543-2011.

Jungclaus, J. H., H. Haak, M. Latif, and U. Mikolajewicz, 2005: Arctic-North Atlantic interactions and multidecadal variability of the meridional overturning circulation. J. Climate, 18, 4013-4031, https://doi .org/10.1175/JCLI3462.1.

Kirtman, B. P., T. Stockdale, and R. Burgman, 2013: The ocean's role in modeling and predicting seasonal-tointerannual climate variations. Ocean Circulation and Climate: A 21st Century Perspective, G. Siedler et al., Eds., International Geophysics Series, Vol. 103, Academic Press, 625-644.

Knight, J. R., R. J. Allan, C. K. Folland, M. Vellinga, and M. E. Mann, 2005: A signature of persistent natural thermohalinec climate. Geophys. Res. Lett., 32, L20708, https://doi .org/10.1029/2005GL024233.

andsea, C. W., and Coauthors, 2004: The Atlantic hurricane database re-analysis project: Documentation for the 1851-1910 alterations and additions to the HURDAT database. Hurricanes and Typhoons: Past Present and Future, R. J. Murname and K.-B. Liu, Eds., Columbia University Press, 177-221. 
Lozier, M. S., 2012: Overturning in the North Atlantic. Annu. Rev. Mar. Sci., 4, 291-315, https://doi.org /10.1146/annurev-marine-120710-100740.

- , and Coauthors, 2017: Overturning in the Subpolar North Atlantic Program: A new international ocean observing system. Bull. Amer. Meteor. Soc., 98, 737-752, https://doi.org/10.1175/BAMS-D-16-0057.1.
Madec, G., 2008: NEMO ocean engine. Institut PierreSimon Laplace Note du Pole de Modélisation 27, $300 \mathrm{pp}$.

McCarthy, G. D., I. D. Haigh, J. J.-M. Hirschi, J.P. Grist, and D. A. Smeed, 2015a: Ocean impact on decadal Atlantic climate variability revealed by sea-level observations. Nature, 521, 508-510, https://doi.org /10.1038/nature14491.

- and Coauthors, 2015b: Measuring the Atlantic meridional overturning circulation at $26^{\circ} \mathrm{N}$. Prog. Oceanogr., 130, 91-111, https://doi.org/10.1016/j.pocean .2014 .10 .006

McGregor, S., A. Timmermann, M. F. Stuecker, M. H. England, M. Merrifield, F.-F. Jin, and Y. Chikamoto, 2014: Recent Walker circulation strengthening and Pacific cooling amplified by Atlantic warming. Nat. Climate Change, 4, 888-892, https://doi.org/10.1038 Inclimate2330.

Morgenstern, O., P. Braesicke, F. M. O'Connor, A. C. Bushell, C. E. Johnson, S. M. Osprey, and J. A. Pyle, 2009: Evaluation of the new UKCA climate-composition model-Part 1: The stratosphere. Geosci. Model Dev., 2, 43-57, https://doi.org/10.5194/gmd -2-43-2009.

Otterå, O. H., M. Bentsen, H. Drange, and L. Suo, 2010: External forcing as a metronome for Atlantic multidecadal variability. Nat. Geosci., 3, 688-694, https:// doi.org/10.1038/ngeo955.

Parrish, D. D., and Coauthors, 2014: Long-term changes in lower tropospheric baseline ozone concentrations: Comparing chemistry-climate models and observations at northern midlatitudes. I. Geophys. Res. Atmos., 119, 5719-5736, https://doi.org phys. Res. Atmos., 119, $5710.1002 / 2013$ J021435.

Prather, M. J., and Coauthors, 2017: Global atmospheric chemistry-Which air matters. Atmos. Chem. Phys., 17, 9081-9102, https://doi.org/10.5194/acp-17-9081 $-2017$.

Robson, J., D. Hodson, E. Hawkins, and R. Sutton, 2014: Atlantic overturning in decline? Nat. Geosci., 7, 2-3, https://doi.org/10.1038/ngeo2050.

- P. Ortega, and R. Sutton, 2016: A reversal of climatic trends in the North Atlantic since 2005. Nat. Geosci, 9, 513-517, https://doi.org/10.1038/ngeo2727.

Schamm, K., M. Ziese, A. Becker, P. Finger, A. MeyerChristoffer, U. Schneider, M. Schröder, and P. Stender,
2014: Global gridded precipitation over land: a description of the new GPCC first guess daily product. Earth Syst Sci Data, 6, 49-60, https//doiorg/10.5194 lessd-6-49-2014. Sheen, K. L., D. M. Smith, N. J. Dunstone, R. Eade, D. P. Rowell, and M. Vellinga, 2017: Skilful prediction of Sahel summer rainfall on inter-annual and multiyear timescales. Nat. Commun., 8, 14966, https://doi .org/10.1038/ncomms14966.

Smith, D. M., R. Eade, N. J. Dunstone, D. Fereday, J. M. Murphy, H. Pohlmann, and A. A. Scaife, 2010 Skilful multi-year predictions of Atlantic hurricane frequency. Nat. Geosci., 3, 846-849, https://doi.org /10.1038/ngeo1004.

Sutton, R. T., and B. Dong, 2012: Atlantic Ocean influence on a shift in European climate in the 1990s. Nat. Geosci., 5, 788-792, https://doi.org/10.1038/ngeo1595. Swingedouw, D., P. Ortega, J. Mignot, E. Guilyardi, V. Masson-Delmotte, P. G. Butler, M. Khodri, and R. Séférian, 2015: Bidecadal North Atlantic ocean circulation variability controlled by timing of volcanic eruptions. Nat. Commun., 6, 6545, https://do .org/10.1038/ncomms7545.

Thiéblemont, R., K. Matthes, N.-E. Omrani, K. Kodera, and F. Hansen, 2015: Solar forcing synchronizes decadal North Atlantic climate variability. Nat. Commun 6, 8268, https://doi.org/10.1038 /ncomms9268.

Timmermann, A., M. Latif, R. Voss, and A. Grötzner 1998: Northern Hemispheric interdecadal variability: A coupled air-sea mode. J. Climate, 11, 1906-1931, https://doi.org/10.1175/1520-0442-11.8.1906.

Trenberth, K. E., and D. J. Shea, 2006: Atlantic hurricanes and natural variability in 2005. Geophys. Res. Lett. 33, L12704, https://doi.org/10.1029/2006GL026894. urner, A. J., C. Frankenberg, P. O. Wennberg, and D. J. Jacob, 2017: Ambiguity in the causes for decadal trends in atmospheric methane and hydroxyl. Proc. Natl. Acad. Sci. USA, 114, 5367-5372, https://doi .org/10.1073/pnas.1616020114.

Walters, D. N., and Coauthors, 2011: The Met Office Unified Model Global Atmosphere 3.0/3.1 and JULES Global Land 3.0/3.1 configurations. Geosci. Model Dev., 4, 919-941, https://doi.org/10.5194 /gmd-4-919-2011.

Williams, K. D., and Coauthors, 2015: The Met Office global coupled model 2.0 (GC2) configuration. Geosci. Model Dev., 8, 1509-1524, https://doi.org/10.5194 /gmd-8-1509-2015.

Yeager, S. G., and J. I. Robson, 2017: Recent progress in understanding and predicting Atlantic decadal climate variability. Curr. Climate Change Rep. 3 112-127, https://doi.org/10.1007/s40641-017-0064-z.
Yuan, T., L. Oreopoulos, M. Zelinka, H. Yu, J. R. Norris, M. Chin, S. Platnick, and K. Meyer, 2016: Positive low cloud and dust feedbacks ampify tropical North Atlantic meltidecadas osillation. Ceophs. Res. Let 43,1349-1356, htt Zhang R and L. Diwo methidead oscihtinson

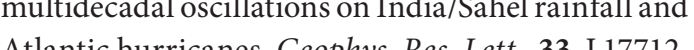
Atlantic hurricanes. Geophys. Res. Lett., 33, L1771 https://doi.org/10.1029/2006GL026267.
- and Coauthors, 2013: Have aerosols caused the observed Atlantic multidecadal variability? J. At mos. Sci, 70, 1135-1144 https//doi.org/10.1175/JAS -D-12-0331.1.

R. Sutton, G. Danabasoglu, T. L. Delworth, W. M. Kim, J. Robson, and S. G. Yeager, 2016: Comment on "The Atlantic multidecadal oscillation without a role for ocean circulation." Science, 352, 1527-1527, https://doi.org/10.1126/science.aaf1660. 


\begin{abstract}
Atlantic multidecadal variability (AMV) is the term used to describe the pattern of variability in North Atlantic sea surface temperatures (SSTs) that is characterized by decades of basinwide warm or cool anomalies, relative to the global mean. AMV has been associated with numerous climate impacts in many regions of the world including decadal variations in temperature and rainfall patterns, hurricane activity, and sea level changes. Given its importance, understanding the physical processes that drive AMV and the extent to which its evolution is predictable is a key challenge in climate science. A leading hypothesis is that natural variations in ocean circulation control changes in ocean heat content and consequently AMV phases. However, this view has been challenged recently by claims that changing natural and anthropogenic radiative forcings are critical drivers of AMV. Others have argued that changes in ocean circulation are not required. Here, we review the leading hypotheses and mechanisms for AMV and discuss the key debates. In particular, we highlight the need for a holistic understanding of AMV. This perspective is a key motivation for a major new U.K. research program: the North Atlantic Climate System Integrated Study (ACSIS), which brings together seven of the United Kingdom's leading environmental research institutes to enable a broad spectrum approach to the challenges of AMV. ACSIS will deliver the first fully integrated assessment of recent decadal changes in the North Atlantic, will investigate the attribution of these changes to their proximal and ultimate causes, and will assess the potential to predict future changes.
\end{abstract}

